\title{
TİP 2 DİYABETLİ HASTALARDA DİYABET SÜRESİ VE HBA1C DÜZEYLERİ İLE OLFAKTÖR DİSFONKSIYYON ARASINDAKİ İLIŞKİ, PİLOT ÇALIŞMA
}

\author{
Relationship between Duration of Diabetes, HbAlc Levels and Olfactory Dysfunction in \\ Patients with Type 2 Diabetes: A Pilot Study
}

\author{
Muhammed Emin DEMIRKOL ${ }^{1}$, Muhammed Nur ÖGÜN² ${ }^{2}$ Hamit YOLDAŞ ${ }^{3}$, \\ İbrahim KARAGÖZ3 ${ }^{3}$, Duygu ÇALIŞKAN ${ }^{3}$
}

\author{
${ }^{1}$ Türkiye Kamu Hastaneleri İzzet Baysal Devlet Hastanesi Dahiliye Kliniği, BOLU \\ 2 Abant İzzet Baysal Üniversitesi Tıp Fakültesi Nöroloji A.D., BOLU \\ ${ }^{3}$ Abant İzet Baysal Üniversitesi Tip Fakültesi Anesteziyoloji ve Reanimasyon A.D,. BOLU
}

Amaç: Bu çalışmada Tip 2 diyabetes mellitus (DM) tanısı olan hastaların diyabet süreleri ve $\mathrm{HbAlc}$ seviyelerinin olfaktör disfonksiyon ile ilişkili olup olmadı̆̆ını araştırmayı amaçladık.

Hastalar ve Yöntem: Önceden bilinen Tip 2 DM tanısı alan ve bu nedenle ilaç kullanan 50 hasta çalışmaya dahil edildi. Hastaların koku fonksiyonlarını test etmek için 12 farklı koku maddesi bulunan The Brief Smell Identification Test (B-SIT) Türkçe versiyonu kullandı. Çalışmaya katılan hastaların yaş, kilo, boy, kilo, HbA1C seviyeleri, diyabet süreleri ve test sonuçları kaydedilerek gerekli analiz yapıldı. p değeri $<0.05$ istatistiksel olarak anlamlı kabul edildi.

Bulgular: Diyabet süresi ve HbA1c düzeyleri ile B-SIT skorlar1 arasında anlamlı korelasyon saptanmadi.

Sonuç: Daha uzun süreli DM'si olan hastalarla yapılacak çalışmalara ihtiyaç vardır.

Anahtar Kelimeler: Brief Smell Test, Diyabet, HbAlc, Olfaktör Disfonksiyon
Introduction: We aimed to investigate whether duration of diabetes and HbA1c levels in patients with Type 2 diabetes mellitus (DM) are associated with olfactory dysfunction.

Material and Methods: Fifty patients with prior Type 2 DM diagnoses under antidiabetic treatment were included to the study. We used the Turkish version of The Brief Smell Identification Test (B-SIT) including 12 different odorants to test the odor functions of patients. Age, weight, height, HbA1C levels, duration of diabetes and test results of the patients participating in the study were recorded and necessary analysis was performed. $\mathrm{p}$ value $<0.05$ was considered statistically significant.

Results: There was no significant correlation between duration of diabetes and $\mathrm{HbA} 1 \mathrm{c}$ levels and B-SIT scores.

Conclusion: In order to confirm our findings further studies with larger sample sizes, with patients with longer duration of DM are needed.

Keywords: The Brief Smell Test, Diabetes, HbAlc, Olfactory Dysfunction 


\section{GíRiş}

Diyabetes Mellitus (DM) sıklığı gittikçe artan sistemik bir hastalıktır. Hastaların \%50'sinden fazlasında sensoryal, motor ve otonomik disfonksiyona neden olan diyabetik periferik nöropati de dâhil olmak üzere birçok sistemik komplikasyona yol açmaktadır. Diyabet ayrıca santral sinir sisteminde yaygin bir nörodejenerasyona neden olmaktadır (1). Diyabette hastanın tanı konulduğu andaki yaşı ve mevcut yaşı, diyabet süresi makrovasküler olaylar ve ölüm açısından bağımsız risk faktörü iken, mikrovasküler olay gelişimi için, genç yaş grubunda daha yüksek olmak üzere, sadece diyabet süresi bağımsız risk faktörü olarak kabul edilmektedir (2). Glikolize hemoglobin (HbA1c) DM'de uzun dönem glisemik kontrolü değerlendirmek amacıyla kullanılan bir parametredir. Yüksek HbA1c düzeyleri diyabetik hastalarda makrovasküler ve mikrovasküler komplikasyonların gelişimi ile yakından ilişkilidir (3).

Diğer duyularla karşılaştırıldığında koku duyusunun öneminin klinikte göz ardı edildiği bir gerçektir. Ancak koku duyusunun bozulması hayat kalitesini oldukça etkilemektedir. Olfaktör sistem endokrin sistemle ilişki içindedir. İnsülin, ghrelin ve leptin hormonlarının olfaktör modulasyon üzerine etkili olduğu yönündeki veriler gittikçe artmaktadır (4-6). Literatürde diyabet ile olfaktör disfonksiyon arasında bir ilişki bulunmuş ve diyabetik komplikasyonları olanlarda olfaktör skorlar düşük bulunmuştur. Ancak bu konudaki kanıtlar sinırlıdır. Hem mikrovasküler hem de makrovasküler komplikasyonlar diyabetik hastalardaki olfaktör disfonksiyon açısından suçlanmıştır. Olfaktör disfonksiyonun diyabetin komplikasyonlarının erken bulgusu olabileceğini öne sürülmüş ve olfaktör testlerin diyabetik komplikasyonların erken tanısında kullanılabileceğini iddia edilmiştir. Diyabetik komplikasyonların yüksek mortalite ve morbiditesi ve yaşam kalitesini etkilemesi nedeniyle erken tanısının yapılabilmesi önem arz etmektedir (7).
Biz bu çalı̧̧mada olfaktör disfonksiyon ile diyabet süresi ve HbA1C değerleri arasında ilişki olup olmadığını araştırmayı amaçladık.

\section{HASTALAR VE YÖNTEM}

Yerel Etik Kurul onamı alındıktan sonra çalı̧̧maya Abant İzzet Baysal Üniversitesi Üniversitesi Tip Fakültesi Anesteziyoloji ve Reanimasyon polikliniğine ve İzzet Baysal Devlet Hastanesi Dahiliye polikliniğine müracaat eden, en az 2 yıldır bilinen Tip 2 DM tanısı olan ve bu nedenle ilaç kullanan 50 hasta dahil edildi. Hastaların son 2 yıl içinde 6 ay aralıklarla yapılmış olan 4 ayrı HbAlc değeri retrospektif olarak kaydedildi. Alt ve üst solunum yolu hastalığı, burun ve sinüslerinde inflamatuvar hastalığı, allerjik riniti, nasal polipi, alkol ve madde bağımlılığı olan hastalarla, mental retarde, alzheimer ve psikiyatrik hastalı̆g olan hastalara ek olarak burun ameliyatı geçirmiş olan ve daha önceden kafa travmasına maruz kalan hastalar çalışma dışı bırakıldı. Bütün hastaların yaş, cinsiyet, boy, kilo kaydedildi. Hastaların koku hafizalarını test etmek için 12 farklı koku maddesi bulunan The Brief Smell Identification Test (B-SIT) Türkçe versiyonu kullandı. $\mathrm{Bu}$ test etiket kazınınca ortama salınan kokuyu tanımaya dayalıdır. Bunun için 4 tane kokulu madde şıkkı verilip içinden doğru olanın tanınması istendi. Hasta 12 soru üzerinden değerlendirildi. Çalışmaya katılan hastaların yaş, kilo, boy, kilo, son iki yıl içinde 6 ay aralıklarla yapılmış 4 ayrı HbAlC değeri, diyabet süreleri ve test sonuçları kaydedilerek gerekli analiz yapıldı.

\section{İstatistik}

Verilerin analizi Statistical Package for Social Science (SPSS 15.0) programı kullanılarak yapıldı. Yaş, boy, kilo, BKİ (Beden kitle indeksi), diyabet süresi gibi tanımlayıcı değişkenler ortalama \pm standart sapma biçiminde gösterildi ve Paired-Samples $\mathrm{T}$ Test kullanılarak veriler karşı1laştırıldı.

Kategorik değişkenlerin karşılaştırılması için Ki-kare Testi kullanıldı. B-SIT skorları ile diyabet süresi ve 
HbA1C değerlerinin korelasyonunun olup olmadiğ araştırmak için (Veriler normal dağılım göstermediğinden) Spearman Korelasyon Testi kullanıldı. Cinsiyet ile BIST skorları arasındaki ilişkiyi saptamak amaciyla Mann-Whitney U Testi kullanıldı. $\mathrm{p}<0,05$ için sonuçlar istatistiksel olarak anlamlı kabul edildi.

\section{BUGULAR}

Bu çalışmaya en az 2 yıldan beridir bilinen Tip 2 DM öyküsü olan ve kliniklerimizde takip edilen 50 (14 erkek, 36 kadın) hasta dahil edildi. Ortalama yaş $(57,2$ $( \pm 8,9)$ idi. Ortalama diyabet süresi $6,9( \pm 5,4)$ yıl idi. (Tablo-1).

Tablo 1: Demografik veriler ve hastaların genel özellikleri

\begin{tabular}{lc}
\hline Hasta Sayısı (n) & $\mathbf{5 0}$ \\
\hline Yaş (yıl) & $57,2( \pm 8,9)$ \\
Cinsiyet (Erkek/Kadın) & $14 / 36$ \\
Boy $(\mathrm{cm})$ & $161,6( \pm 9,1)$ \\
Vücut Ağırlı̆̆ı $(\mathrm{kg})$ & $81,7( \pm 14,7)$ \\
BKİ $\left(\mathrm{kg} / \mathrm{m}^{2}\right)$ & $31,4( \pm 5,7)$ \\
Diyabet Süresi $(\mathrm{y} 1)$ & $6,9( \pm 5,4)$ \\
HbA1C $1 *(\mathrm{gr} / \mathrm{dl})$ & $8,1( \pm 1,7)$ \\
HbA1C $2(\mathrm{gr} / \mathrm{dl})$ & $7,7( \pm 1,3)$ \\
HbA1C $3(\mathrm{gr} / \mathrm{dl})$ & $7,6( \pm 1,5)$ \\
HbA1C $4(\mathrm{gr} / \mathrm{dl})$ & $7,3( \pm 1,1)$
\end{tabular}

*2 y1l önce bakılan HbA1C değeri HbAlc 1, son bakılan HbA1c değeri HbA1c 4 olarak 6 aylık aralıklarla kategorize edildi.

Spearman korelasyon ile hastların diyabet süreleri ve HbA1c değerlerinin B-SIT skorları arasında korelasyon saptanmadi (p:0.564, korelasyon katsayısı: 0.084) (Şekil 1).

Kadın hastlarda B-SIT skoru erkek hastalardan daha yüksek bulundu. (p: 0.033) BKİ ile olfaktör disfonksiyon arasında anlamlı korelasyon saptanmadı. (p: 0.617, korelasyon katsayıs1: 0.072). Sigara kullanımı, hiperlipidemi ve kardiyovasküler hastalık varlığı olfaktör disfonksiyon ile ilişkili bulunmadı (p: $0.514)$.

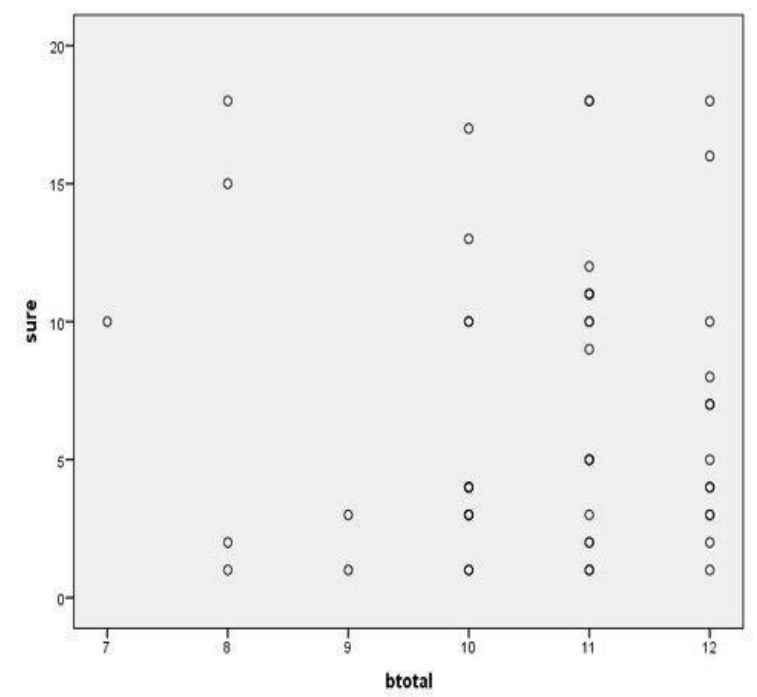

Şekil 1: Diyabet süresi ile BIST skorları arasında anlamlı korelasyon saptanmadi. (rho: 0.084, p:0.564) Btotal: B-SIT skorlarl, Süre: Diyabet süresi

\section{TARTIŞMA}

$\mathrm{Bu}$ çalışmamızda olfaktör disfonksiyon ile diyabet süresi ve HbA1C değerleri arasında ilişki bulunmamıştır. DM toplumda çok sık görülen ve komplikasyonları geliştiğinde yaşam kalitesini oldukça bozan kronik bir rahatsızlıktır. Hiperglisemiye bağlı akut etkilerden çok, gerek kötü kan şekeri kontrolüne bağlı gerekse uzun yıllar içerisinde hastalığın kaçınılmaz sonucu olan kronik komplikasyonlar açısından oldukça önemli ve takibi zorunludur (8). Yakın takipteki amaç, hedeflenen glukoz düzeyini sağlamakla birlikte gelişebilecek diyabetik nefropati, nöropati, retinopati gibi mikrovasküler, serebrovasküler, periferik vasküler gibi makrovasküler komplikasyonları önceden tespit ederek gerekli tedbirleri almaktır. Çünkü kontrolsüz diyabete bağlı inflamatuar süreçler tetiklenmekte, organ sistemlerine etkisi sonucunda uzun dönemde bu tip komplikasyonlar gelişebilmektedir (9). Çoğunluğu farkında olmadan gelişen bu komplikasyonların 
zamanında tespiti mortalite ve morbiditeyi azaltmakla birlikte hastanın kaliteli bir yaşantı sürmesine de olanak sağlamaktadır $(8,10)$. HbA1c, DM olan hastalarda kan şekeri regülasyonunu gösteren önemli bir parametredir. Yapılan pek çok çalışmada diyabet süresi ve HbAlc seviyesinin yüksekliği ile kronik komplikasyon gelişmesi arasında anlamlı ilişki olduğu bildirilmektedir $(11,12)$.

Koku fonksiyonu insan için vazgeçilmez fizyolojik bir ihtiyaçtır. Literatürde koku fonksiyon kaybının \%4 oranında sıklıkla ileri yaşlarda olduğu bildirilmektedir (13). Burunda regio olfactoria'da algılanan koku beyne bulbus olfactoriusda girmektedir. Buradan da tractus olfaktorius ve stria olfaktorius yoluyla olfaktor kortekse uzanmaktadır. Beyinde koku hafizası priform korteks, amgydala ve enthorinal korteksde yer almaktadır (14). Koku, bilgilerin talamusa uğramadan bulbustan direkt kortikal alanlara iletildiği tek duyudur (15).

Naka ve arkadaşları Tip 1 ve Tip 2 DM'li hastalarda koku ve tat duyusunun bozukluklarını araştırdıkları bir çalışmada, Tip2 diyabetli hastalarda olfaktor disfonksiyonun daha fazla olduğunu, Beden Kitle İndeksi (BKİ) ile olfaktör disfonksiyon arasında negatif korelasyon olduğunu göstermişlerdir (16). Ayrıca HbA1c ve diyabet süresinin olfaktör disfonksiyonla korelasyon göstermediğini bildirmişlerdir. Biz çalışmamızda BKİ ile olfaktör disfonksiyon arasında anlamlı korelasyon saptamadik, HbAlc ve diyabet süresi ile olfaktör difonksiyon arasında da Naka ve arkadaşlarının çalışmasına paralel olarak korelasyon izlemedik. Gouveri ve arkadaşları ise Tip2 DM'li hastalarda olfaktör disfonksiyon ile mikrovasküler komplikasyonlar arasındaki ilişkiyi araştıran bir çalışmalarında 10 yılın üzerinde diayebeti olan hastalarda olfaktör disfonksiyonun ortaya çıktığını göstermişlerdir. Le Floch ve arkadaşları da Tip2 DM'li hastalarda diyabet süresi ile olfaktör disfonksiyon arasında pozitif korelasyon saptamışlardır $(7,17)$. Diyabet hastalarında olfaktör disfonksiyonu etkileyen diğer faktörler arasında sigara kullanımı, hiperlipidemi ve eşlik eden kardiyovasküler hastalık varlığı sayılabilir. Her üç faktörün de olfaktör disfonksiyonu üzerine etkisi tartışmalıdır (7). Biz çalışmamızda sigara kullanımının, hiperlipideminin ve kardiyovasküler hastalık varlığının olfaktör disfonksiyon üzerinde etkisine rastlamadik. Olfaktör disfonksiyonun antidiyabetik kullanımı ile ilişkili olup olmadığını araştıran Weinstock ve arkadaşları sadece sulfanilüre kullanımının olfaktör disfonksiyon ile ilişkili olduğunu göstermişlerdir (18). Literatürde antidiyabetik ilaçların olfaktör disfonksiyon üzerine etkisini araştıran başka bir çalışmaya rastlamadık. Çalışmamızda sülfanilüre kullanımının korelasyonunun istatistiksel değerlendirmesini yapacak sayıda ilaç kullanan hasta bulunmamaktaydı. Literatürdeki diyabet olfaktör disfonksiyon ilişkisini gösteren çalışmaların birbirinden farklı sonuçlar vermesi olfaktör fonksiyonu değerlendirmede kullanılan testlerin farklılığg da olabilir. Weinstock ve arkadaşları Odorant Confusion Matrix (OCM) adı verilen tamamen kimyasal içerikli dilüe edilmiş 10 kimyasal maddenin kullanıldı $\breve{g}_{1}$ bir yöntem kullanmışken, Le Floch ve arkadaşları 24 aromanın olduğu bir test kullanmışlardır $(17,18)$. Gouveri ve arkadaşları ise 112 kokulu çubuğun kullanıldığı koku değerlendirme, koku eşik değerinin ve lokal patolojilerin dişlanabileceği nispeten daha kompleks bir test kullanmışlardır (7). Biz çalışmamızda The Brief Smell Test (B-SIT) adı verilen koku testi kullandık. B-SIT kültürel farklılıklar düşünülerek hazırlanmıştır. On iki farklı koku içeren bu test The Cross-Cultural Smell Identification Test (CC-SIT) olarakta bilinmektedir (19). Birçok çalışmada bu test kullanılarak koku hafizası değerlendirilmiştir (20-22).

Yapılan çalışmalarda olfaktör disfonksiyon ile cinsiyet arasında farklılık izlenmezken, biz çalışmamızda kadın hasta grubunda olfaktör tanıma B-IST skorlarını erkeklerden daha yüksek bulduk. Bunun kadınların koku algılarının daha gelişmiş ve iyi olmasından kaynaklandığını düşündük. Guerneri ve arkadaşlarının ve Weinstock ve arkadaşlarının yaptı̆̆ı çalışmada diyabetik hastalardaki olfaktör disfonksiyon cinsiyetler 
arasında farklılık göstermezken, bizim çalışmamızda kadın hasta grubunda olfaktör tanıma B-IST skorları erkeklerden daha yüksek bulunmuştur $(7,18)$.

Literatür araştırmamızda Tip 2 DM'u olan hastalarda koku fonksiyonunun değerlendirildiği çalışmalarda birbirinden farklı sonuçlar olmakla beraber koku fonksiyonunun Tip2 DM'li hastalarda bozulduğu yönünde çalışmaların sayısı nisbeten fazladır. Çalışmamızda, literatürdeki çalışmalardan farklı olarak, HbA1c düzeyi ve DM süresi ile koku fonksiyon bozukluğu arasında bir korelasyon gözlenmedi. $\mathrm{Bu}$ durumu çalışma grubumuzun Tip 2 DM hastaları olmasına ve DM süresinin kronik komplikasyon gelişecek kadar uzun olmamasına bağladık.

Çalışmamızın sınırlılıkları; hasta sayımızın az olması, Tip 1 DM'u olan hastaların çalışmaya dahil edilmemesi, daha uzun süre Tip 2 DM'u olan hastaların çalışmada az yer alması, mikrovasküler komplikasyon olan ya da olmayan hastaların koku fonksiyon değerlendirmelerinin ayrıca yapılmamış olmasıdır.

Sonuç olarak literatürde ilk defa Tip 2 DM'nin kısa dönemli koku belleğini etkilemediğini gözlemledik. Bulgularımızı doğrulamak için daha büyük örneklem büyüklüğüyle, daha uzun DM'u olan hastalarla yapılacak ileri çalışmalar gerekecektir.

Çıkar Çatışması: Yok

\section{KAYNAKLAR}

1. Brady, S., et al., Presence of neuropathic pain may explain poor performances on olfactory testing in diabetes mellitus patients. Chemical senses, 2013: p. bjt013.

2. Zoungas, S., et al., Impact of age, age at diagnosis and duration of diabetes on the risk of macrovascular and microvascular complications and death in type 2 diabetes. Diabetologia, 2014. 57(12): p. 2465-2474.

3. Ertem, A.G., et al., Relationship between HbA1c levels and coronary artery severity in nondiabetic acute coronary syndrome patients. Turk Kardiyol Dern Ars, 2013. 41(5): p. 389-95.

4. Hoffman, H.J., K.J. Cruickshanks, and B. Davis, Perspectives on Population-based Epidemiological Studies of Olfactory and Taste Impairment. Annals of the New York Academy of Sciences, 2009. 1170(1): p. 514-530.

5. Hummel, T. and S. Nordin, Olfactory disorders and their consequences for quality of life. Acta otolaryngologica, 2005. 125(2): p. 116-121.

6. Palouzier-Paulignan, B., et al., Olfaction under metabolic influences. Chemical senses, 2012. 37(9): p. 769-797.

7. Gouveri, E., et al., Olfactory dysfunction in type 2 diabetes mellitus: an additional manifestation of microvascular disease? Angiology, 2014. 65(10): p. 869-876.

8. Özşenel, E.B., et al., Diyabetik Mikrovasküler Komplikasyonu Olan ve Olmayan Hastaların MPV ve Sensitif CRP Düzeylerinin Karşılaştırılması. Medical Bulletin of Haseki/Haseki Tip Bulteni, 2015. 53(1).

9. Sobel, B.E., Optimizing cardiovascular outcomes in diabetes mellitus. The American journal of medicine, 2007. 120(9): p. S3-S11.

10. Yenigün, M., Diabetik makroanjiopati (diabetik makrovasküler hastalık) Her yönüyle Diabetes Mellitus adlı kitabından Editör: Yenigün M. Nobel T1p Kitabevi, 2001.

11. Al-Salman, R., et al., Prevalence and risk factors of albuminuria in Type 2 diabetes in Bahrain. Journal of endocrinological investigation, 2009. 32(9): p. 746-751.

12.Zhang, H., et al., Prevalence of and risk factors associated with diabetic retinopathy in pre-diabetic and diabetic population in Shanghai community. Zhonghua yi xue za zhi, 2009. 89(25): p. 17491752.

13. Henkin, R.I., Altered Taste and Smell after AnesthesiaCause and Effect? The Journal of the 
American Society of Anesthesiologists, 1995.

83(3): p. 648-649.

14. Rombaux, P., T. Duprez, and T. Hummel, Olfactory bulb volume in the clinical assessment of olfactory dysfunction. Rhinology, 2009. 47(1): p. 3-9.

15. Cullen, M.M. and D.A. Leopold, Disorders of smell and taste. Medical Clinics of North America, 1999. 83(1): p. 57-74.

16. Naka, A., et al., Clinical significance of smell and taste disorders in patients with diabetes mellitus. European Archives of Oto-Rhino-Laryngology, 2010. 267(4): p. 547-550.

17. Le Floch, J.-P., et al., Smell dysfunction and related factors in diabetic patients. Diabetes Care, 1993. 16(6): p. 934-937.

18. Weinstock, R.S., H.N. Wright, and D.U. Smith, Olfactory dysfunction in diabetes mellitus. Physiology \& behavior, 1993. 53(1): p. 17-21.

19. Menon, C., et al., Normative Performance on the Brief Smell Identification Test (BSIT) in a MultiEthnic Bilingual Cohort: A Project FRONTIER Study 1. The Clinical neuropsychologist, 2013. 27(6): p. 946-961.

20. Bilgi, M., et al., Effects Of Isoflurane On Postoperative Olfactory Memory. Acta Medica Mediterranea, 2014. 30: p. 453-456.

21. Demirhan, A., et al., Evaluation of the olfactory memory after spinal anesthesia: a pilot study. Age (yr), 2013. 32: p. 13.9.

22. Yildiz, I., et al., The effect of desflurane on postoperative olfactory memory. European review for medical and pharmacological sciences, 2016. 20(10): p. 2163-2167. 